\title{
Public information strategies: Making government information available to citizens
}

\author{
Albert Meijer ${ }^{\mathrm{a}, *}$ and Marcel Thaens ${ }^{\mathrm{b}}$ \\ ${ }^{a}$ Utrecht School of Governance, Bijlhouwerstraat 6, 3511 ZC Utrecht, The Netherlands \\ ${ }^{\mathrm{b}}$ Ordina Public Management Consulting and Erasmus University Rotterdam/FSS/Public \\ Administration, PObox 1738, 3000 DR Rotterdam, The Netherlands
}

\begin{abstract}
New technological opportunities and increasing demands make it imperative for government agencies to make the information they gather available to citizens. How should they go about this? This paper presents a conceptual framework for analyzing the strategic options open to agencies which have information that could be relevant to citizens. The conceptual framework is constructed on the basis of the literature and tested in a case study. The Directorate-General for Public Works and Water Management in the Netherlands gathers traffic information which is useful for citizens when they want to avoid traffic jams. Presently, the agency sells information to intermediaries. The agency wanted to release the information through its own website but this was prohibited by a court ruling. This paper reviews other strategies and proposes that an 'Intel inside' strategy may be a viable option in view of the consequences for effectiveness, manageability, cost-effectiveness, equity and legitimacy. The paper concludes that the conceptual framework proves useful for analyzing the strategic options open to agencies for making government information available to citizens.
\end{abstract}

Keywords: Information strategy, analytic framework, public information, structuration

\section{Introduction}

Government agencies gather a variety of sorts and forms of information as a part of their tasks [1,2]. In the Netherlands, governments gather data on air pollution to design better policies. Information about school quality is gathered and created as school inspections inspect the quality of schools. The food inspection creates data in through their inspections of restaurants and other premises. The army creates geographical data for their maps of the country. All these data are needed for government functions but they could also be useful for citizens and other actors in society.

Presently, government organizations all around the world are reviewing and rearranging their information relations with outside parties and citizens [3-5]. They explore means to make better use of all their information to inform citizens on a variety of issues such as traffic information, environmental quality, food safety, school quality, etc. Informing citizens may be a way to improve policies and enhance government legitimacy. Additionally, selling information may be a good way to enhance agency income and hence government funding for agencies could be reduced.

New information arrangements need to be understood within the context of two broad trends. The first trend is the increase in technological opportunities. Opportunities for disseminating information

\footnotetext{
${ }^{*}$ Corresponding author. E-mail: a.j.meijer@uu.nl.
} 
have improved immensely and, consequently, a reduction of the costs involved in making information available to citizens. The Internet enables agencies to connect datasets to a website and enable citizens to access the data in a wide variety of ways. Technological developments have also facilitated the gathering of data through processes of 'informating' [6]: every automated government operation generates new data which can be useful for citizens.

The second trend involved in changing information arrangements is the increasing participation of stakeholders in government policies [7]. Traditional ideas about government as the central actor in society have changed into regarding steering as the output of the efforts of various actors such as nongovernmental organizations and companies. Government increasingly cooperates with other actors in policy networks and public-private partnerships. Information arrangements increasingly reflect these patterns of relations between government agencies and other actors $[8,9]$.

These opportunities and trends enable and stimulate government agencies to make new choices regarding their information arrangements. In this paper we will explore the factors that are involved in making these choices. We will present a case study from the Netherlands to enhance our understanding of the factors involved in deciding about information arrangement. The goal of this paper is not to single out one best way information arrangement but to enhance our understanding of factors and considerations involved in choosing these arrangements.

This paper focuses on the Dutch context but we claim that the framework developed can also be applied to other contexts since it is based on general assumptions and arguments. For the reader it may nevertheless be useful to obtain information on the Dutch context to evaluate the validity of our claim. In the Dutch context, government organizations gather a wide variety of information to carry out their legal tasks. Most information falls under the legal right of access to information but the law is not explicit about the efforts government organizations should make to facilitate its use by citizens. Government organizations have a large degree of autonomy in information management. In our analysis we focus on the way government use this autonomy to make information available to citizens.

\section{Rational choices and institutional rules}

Decisions on information arrangements can be studied as rational actions within certain institutional contexts [10-12]. To understand these rational actions we need to understand the preferences of government agencies and the options open to them. Institutional contexts can be studied by investigating the formal and informal rules that guide the behavior of government agencies.

Additionally, decisions about information arrangements cannot be isolated from more encompassing strategic choices: they need to be positioned within the general strategy of agencies for reaching policy goals (see also [13]). This general strategy highlights how the organization aims to reach certain policy goals. An important element of this strategy is the perspective on cooperation with other actors. Does the organization want to take an autonomous and independent position or is cooperation with other actors the preferred strategy? The information strategy needs to fit within this general strategy.

The general preferences of government agencies in choosing an information arrangement can, broadly, be labeled as legitimacy, effectiveness, equity, efficiency and manageability [14].

Legitimacy refers to the acceptance of governance authority and is related to trust in government [11, 15]. The basic idea behind the relation between information arrangement and legitimacy is that granting new services to citizens and improving the visibility of a government agency can enhance its legitimacy (see also [16]). The Dutch School Inspection Service, for example, used to be invisible to citizens 
since their reports were only presented to school management [16]. Now they publish their reports on the Internet and their visibility has increased significantly. Information arrangements could be used strategically to enhance the legitimacy of an agency.

The effectiveness essentially measures the extent to which an activity reaches its intended objectives [14, p. 23]. More specifically, it refers to the attainment of policy goals. Information arrangements can influence the effectiveness of a government agency when making the information available, directs the behavior of stakeholders in a desired direction (for an example, see also the case description).

Equity is a preference which is especially relevant for governments since public authorities are supposed to treat all citizens equally. Equity refers to a basic fairness criterion, i.e. 'the distribution of benefits and costs more or less evenly among all those eligible' [14, p. 23]. There may be reasons to depart from this principle such as affirmative action. But these reasons need to be stated explicitly. For information management this preference mainly refers to equal access to information for all citizens. Inequalities such as creating privileged access to certain information should be avoided.

The criterion 'efficiency' refers to the cost-effectiveness of a government agency [14, p. 23]. What do they deliver at a certain cost? The efficiency increases when the agency manages to carry out its tasks at a lower cost or when they can do more tasks at the same cost. Many agencies are primarily funded out of tax payers' money. Their cost-effectiveness could be increased when the information they gather in the execution of their tasks could be sold to outside parties. This new source of income could partly substitute for tax payers' money. Information arrangements which constitute of selling information to certain actors could thus be a means to enhance agency cost-effectiveness.

Salamon's final preference is 'manageability' which refers to the ease or difficulties in operating programs [14, p. 24]. Translated to information management, this preference indicates that governments should find working arrangements. The examples of governments that face difficulties because of the extensive and complicated datasets they need to manage are abundant. Managing information systems is a specific expertise and choosing manageable information systems is imperative to government agencies.

The general preferences are valued by government agencies in a specific setting. They may attach different degrees of weight to these preferences. Especially when the preferences are conflicting, the importance government agencies attach to the different preferences is relevant. The resulting preferences can be conceptualized as the conglomerate of general preferences with specific meanings multiplied by the weights factors.

Now we know the broad preferences, we can describe the opportunities available to government agencies. Government agencies can choose between the following alternatives:

1. Keeping the information for the agency: the information is not actively released to a wider audience.

2. Presenting the information on a government website to make this information available to both citizens and commercial actors.

3. Selling the information to information intermediaries which offer the information on websites to citizens.

4. Giving the information to information intermediaries which offer the information on websites to citizens.

The difference between options (1) and (2) versus options (3) and (4) is that the latter options require an information intermediary. Changing from options (3) and (4) to option (2) can be regarded as disintermediation [17]. Re-intermediation takes place when traditional intermediaries are being replaced by new intermediaries. The viability of the options (3) and (4) depend to a large extend on the 
availability of intermediaries. Government agencies are forced to choose for either option (2) or refrain from publishing the information on a website (option 1) when no reliable information intermediaries are available. This analysis shows that government choices also depend on strategic behavior of these intermediaries and in that sense the information arrangement should be regarded as a multi-actor game.

Multi-actor behavior is not only relevant when it comes to intermediaries but also when it comes to competitors. The presence of other actors that could offer similar information influences the options open to government agencies. If other actors offer this information for free, government agencies will have a difficult time selling the information.

Choices for the options are made within a certain institutional context. These contexts consist of sets of formal and informal rules that guide the behavior of agencies $[18,19]$. The most direct aspect of the institutional context is the legal framework they operate in. What does the law say about information arrangements? Another aspect of the institutional context is the political environment. This part of the environment is about the expectations and demands from the political system on the agency. Thirdly, the informal rules that guide behavior of actors in the sector are part of the institutional context. What is the normal way of sharing information in the sector?

Legal frameworks relevant to information arrangements are specific to countries and often also differ per policy sector. These frameworks are often highly complicated and they may not be clear on the status of various forms of digital information. In the Netherlands, this framework consists of general laws regarding the freedom of information and proper government behavior. Specific laws relate to the behavior of the agencies which gather information. The Education Inspection Act (Wet op het Onderwijstoezicht), for example, states that the School Inspection Service should provide the sector with neutral information about quality of schools.

The political context influences, among other things, how important it is for the agency to make the information available to the public. In the Netherlands, in 2000 a fireworks factory exploded and this triggered a debate about the availability of information about the environment and risk management. This led to a strong push for making more information available to the public.

Every policy sector had developed a set of informal rules. These rules may stipulate that cooperation is needed and this information needs to be shared. In such a context it would not considered being proper for a government agency to sell this information. On the other hand, informal rules may also emphasize that a commercial attitude leads to better outcomes and hence government agencies may also be expected to act in their own commercial interest.

Rational choices and institutional contexts have so far been treated as separate entities. Giddens' structuration theory, however, states that these are directly related ([20], see also [21]) for an application of this theory to information systems. The institutional context conditions these choices and, at the same time, this institutional context may change through choices. Certain information arrangements can influence the informal rules that guide the behavior of actors in a sector. These arrangements may even influence the legal and political contexts when new rules are needed or political relations change. This means that the choice for a certain information arrangement should not only be studied as a rational choice but also as a process of institutional change.

On the basis of our discussion of rational choices and institutional rules, we can construct the following framework for studying what government agencies do with the information which could be relevant to citizens or stakeholders: 


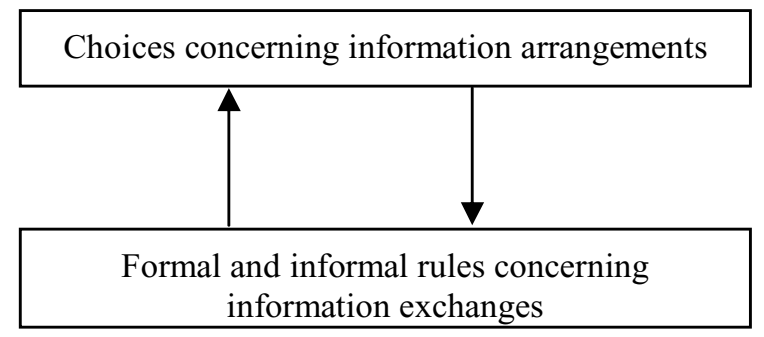

Fig. 1. Choosing an information arrangement as structuration.

1. General strategy. The information strategy of an agency is an aspect of a more general strategy for reaching policy objectives. The core assumptions of this general strategy need to be analyzed to position the information strategy.

2. Preferences. On the basis of this general strategy, agencies define preferences towards the use of information in terms of legitimacy, effectiveness, equity, efficiency and manageability. These preferences form the basis for the choice between strategic options.

3. Other actors. The presence of other actors - most importantly intermediaries and competitors influence the options open to government agencies and therefore needs to be analyzed.

4. Institutional context. The institutional context also limits the options open to government agencies. Agencies make their choices within legal frameworks, political settings and informal rules. The context needs to be analyzed to understand the strategic options.

5. Strategic options. Various options for using the information can be defined within the institutional context and while considering the presence of other actors. The two basic options are making the information available or not. Additionally, depending on the presence of other actors, agencies can make the information available through intermediaries either by selling the information or giving it to them.

6. Choices. On the basis of the preferences (inferred from the general strategy) and strategic options (within institutional contexts and depending on the presence of other actors), agencies choose for a certain option.

In the next section we want to explore whether this framework can be used to explain the variety of choices in a real setting. The case is used as a testbed for the framework.

\section{Research methodology}

The case we selected - traffic information at the Directorate-General for Public Works and Water Management - can be characterized on the basis of the following aspects:

- The information is directly useful to a large group of citizens, e.g. to reduce their travel times.

- The information can be used to influence the behavior of citizens in a desired direction to reach certain policy objectives. Use of the information by citizens can lead to a reduction in traffic jams.

- Intermediaries are present which are willing and able to present the information to a general public. This presence makes the pallet of available options more encompassing.

These factors make the release of information urgent and the presence of intermediaries creates a larger range of strategic options. Applications of this framework to other contexts may result in a more limited number of strategic options and maybe even trivial outcomes. The framework needs to be tested 
further to show that it can also be applied to contexts other than the critical case and in other institutional regimes. Nevertheless, in the case we studied, the framework shows its value for discerning between various options.

Data for the case study were gathered through website analysis, document analysis [22-24], a study of media publications [25-27] and a control interview with an expert. The following websites were analyzed on December 13th, 2007: www.weginfo.nl, www.rijkswaterstaat.nl, www.verkeerenwaterstaat.nl, www.anwb.nl, www.verkeersinformatiedienst.nl). The analyses of the documents focused on reconstructing (1) the Directorate-General for Public Works and Water Management's general and information strategy, (2) options open for making information available to the general public, (3) consequences attached to these options in terms of the preferences considered, (4) the formal and informal rules that limit or facilitate these options and (5) the presence of other relevant actors in the field. The reconstruction we made was presented to an expert working for RWS to check whether this reconstruction of the case was adequate and complete.

Data has been analyzed on the basis of the theoretical framework to find qualitative patterns. The focus in the analysis was put on preferences, options and choices. The analysis of the general strategy, presence of other actors and institutional context was limited to the aspects that are critical to determining preferences and strategic options.

\section{Case study}

The Directorate-General for Public Works and Water Management (Rijkswaterstaat or RWS) is the organization responsible for the execution of the policy of the Ministry of Transport, Public Works and Water Management (Verkeer en Waterstaat or V\&W). It is responsible for the development and maintenance of the main transport infrastructures in the Netherlands. RWS aims to create a quick and safe circulation of traffic, a safe, clean and user-oriented national water system and the protection of the Netherlands against floods.

Recent developments in politics and in society rendered the traditional strategy of RWS, which was being followed until the beginning of the new millennium, no longer as adequate. Therefore, in its business plan for 2004 RWS a shift in focus was made. From a focus on technology, RWS now turns the focus on the needs of the users of the wet and dry networks. Starting point is the idea that users want to travel from A to B quickly, safely and well informed. A growth of the number of travellers and the number of goods transported by road or water of over a hundred percent is expected in the near future. At the same time it is not expected that the capacity of the roads shall double. The growing utilization of the road infrastructure focused RWS' attention on the users.

RWS has no history of providing information directly to citizens although it has been selling some of its information to commercial parties. Recent technological developments such as the Internet and growing citizen demands for this type of information related to the ever growing traffic jams have made it imperative for this authority to make this information available. This inevitably leads to the question of how this information should be made available to the general public.

In the Netherlands traffic jams are increasingly becoming a societal problem. In 2006 the Dutch together spent 44 million hours waiting in traffic congestions. This is an increase of $11 \%$ in consideration to 2005 . As part of its responsibility RWS collects information on the traffic flows on the national highways. For this purpose RWS uses cameras that can recognize registration numbers of cars on the roads. They also use induction loops that are built into the road surface of the national main roads. 
By measuring information on the flow of the traffic, RWS has real-time information at its disposal regarding the existence and the origination of traffic congestions in the national highway system. In an effort to become more user oriented, RWS decided in 2003 to open up this information for free to the general public. This was done in two ways. First, RWS developed its own website showing a map of all the main roads in the Netherlands (www.weginfo.nl). The information about congestions was shown on these roads with different colors. By looking at the change of colors of certain roads, a user could see immediately where traffic jams were or where they are developing. On the basis of actual traffic information road users could then choose a different route.

An Text Messaging service was a second way of opening up the real-time information by RWS. After subscription to this service, road users received a Text Message stating the actual traffic situation on their route.

In 2003 these releases of the information by RWS led to a lawsuit against RWS [28]. A private organization, the Traffic Information Service (VerkeersInformatieDienst of VID, part of US Telecom), accused RWS of wrongful action. Since 1998, the VID receives traffic information from an organization considered a part of RWS in return for payments and on the basis of an contract for an indefinite period. The VID enriches this information and supplies it as a commercial service to television, radio stations and directly to citizens. For a part citizens can make free use of the information, for example, when they listen to radio stations (that use income from advertisements to pay to the VID). If citizens want more detailed of more 'tailor-made' information they can make use of other commercial VID services. The VID for example also distributes the enriched information through channels like the Internet, a Text Messaging service, mobile phones and Television Text. If RWS delivered the information for free, so they claimed, the VID would suffer losses. The judge ruled in favour of the VID and prohibited RWS from releasing its own information in the ways described earlier. RWS accepted the judge's legal argumentation and has not appealed against the verdict.

The contract between the VID and RWS is grounded in a principal choice regarding government agencies and the execution of what can be considered activities that can also be done by the free market. The line of reasoning underlying this choice is stated in the policy document 'Travel information' (Reisinformatie) issued by the Ministry of Transport, Public Works and Water Management in November 1996. The policy states that the Ministry wants to stimulate the development and exploitation of travel information services but does not consider this development and exploitation itself as a government task. The policy document continues to state that if possible, the market must play its own role. The Ministry stimulates the creativity of entrepreneurship on this issue. Based on this policy the VID pointed out that RWS was not allowed to supply the traffic information to end users. It only has a role in supplying this kind of information to its customers and in guaranteeing the quality and usability of this information. The judge followed the VID in this line of reasoning and therefore favoured the VID in his verdict. So, by opening up their own website in 2003 in an attempt to become more user oriented, RWS had not realized that this would conflict with the policy on travel information that had been developed by the responsible Minister.

Apart from the VID there are other organizations which have similar contracts with RWS. They all receive traffic information from RWS, enrich it with other kinds of information and then deliver it as a commercial service to end users. An example of these services is shown below. Figures 1 and 2 show how a large interest group of road users (ANWB), enriches and opens up the traffic information they initially receive from RWS.

For a long time RWS was unique in its ability to supply real-time traffic information. However, this situation is changing. As a result of new technologies the use of detection devices in the road surfaces 


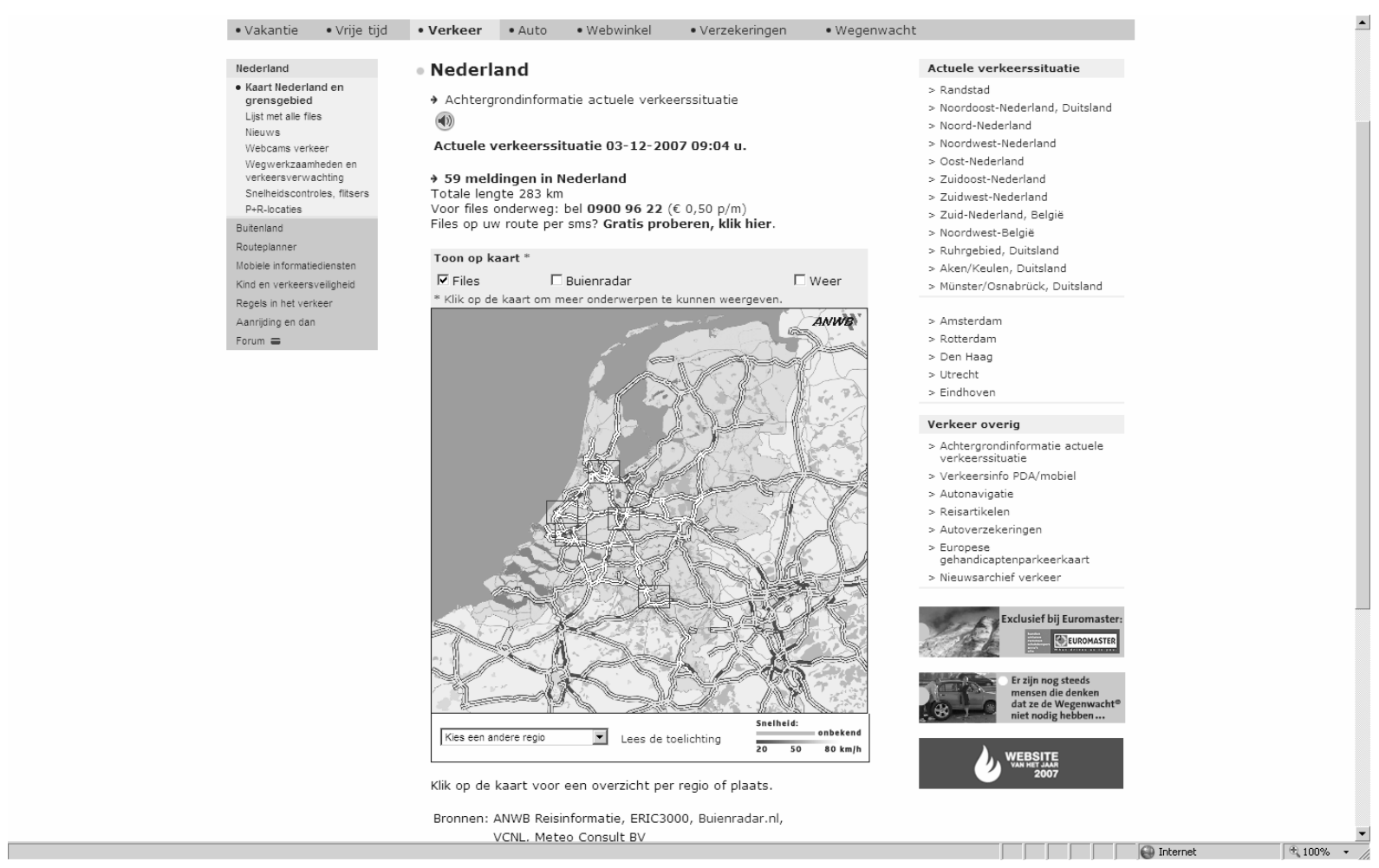

Fig. 2. Realtime information on traffic jams.

is no longer the only source for gathering this kind of information. One example is the data of telecom operators, which can also be used to generate information on the development of traffic jams. At the moment the circulation of traffic on a certain road is slowed down or blocked, the data of the telecom operators show an increase in the number of mobile phones that are moving in a certain direction within a certain cell in the network operated by the telecom provider. One does not need to know which phones are exactly switched on, only the fact that these phones are present in the specific network cell is relevant. So from this anonymous data one can derive that a traffic jam on a certain road arises. In this way in the Netherlands a telecom operator (Vodafone) supplies traffic information to a manufacturer of navigation system for in car use (TomTom) [22].

This manufacturer uses this data to optimize its (paid) services to end users. The solution is available from the end of 2007 and is the world's first nationwide commercial deployment of this kind. An advantage over the earlier ways of gathering data about traffic jams is that this new way is not restricted to the main roads. The induction loops are only built into the national highway system. The new way is not restricted to these highways but can also be used for collecting traffic data for other kinds of roads like for example provincial highways and local roads. The solution will be made available for consumers but also for road authorities and businesses, who may use it for dynamic traffic control measures and improved fleet management. This development implies that RWS is losing its monopoly on the gathering of traffic data. Now competitors can generate and supply comparable data. 


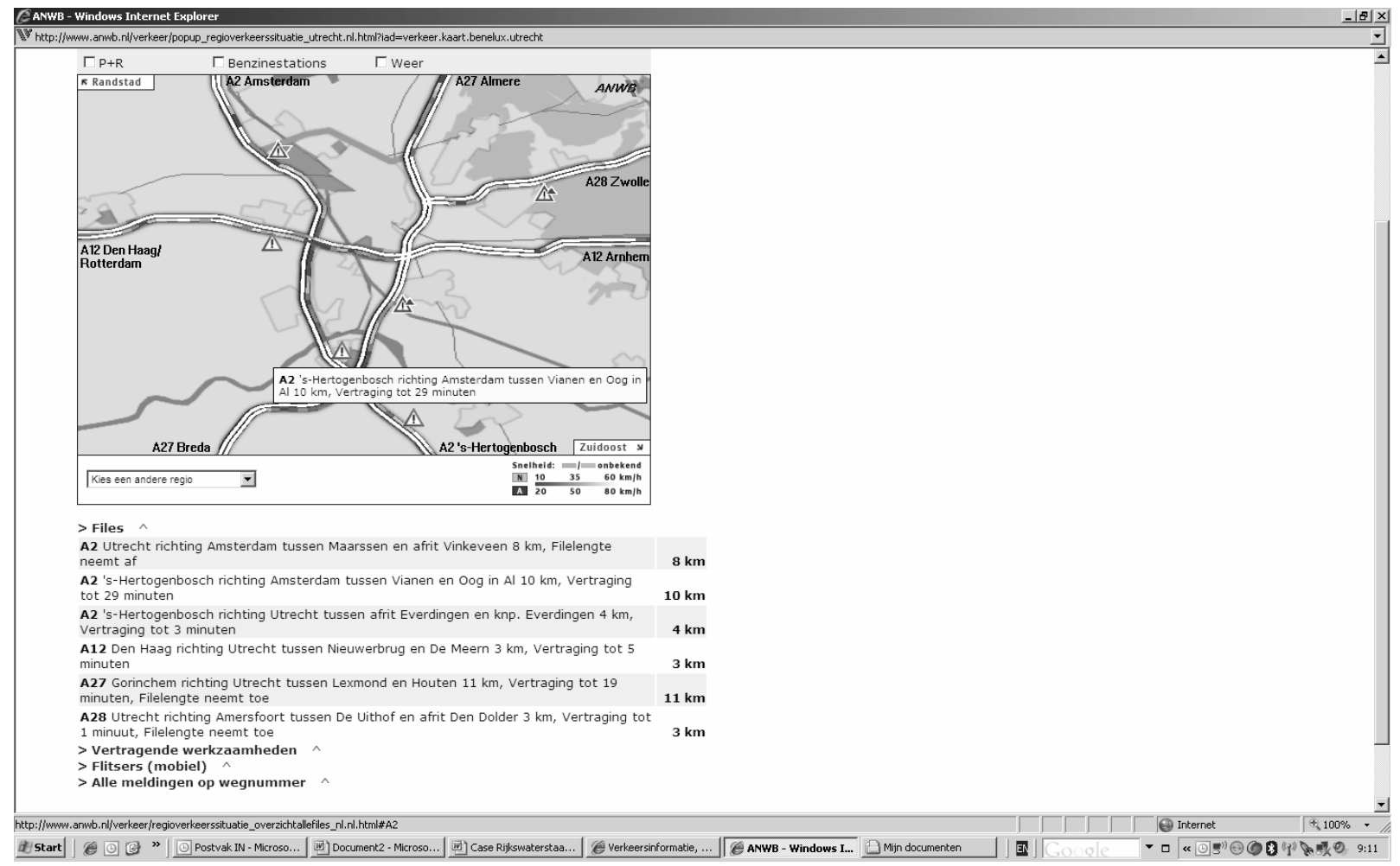

Fig. 3. Zoom on one of the bottlenecks.

\section{Analysis of the case}

The RWS case has been described to show the intricacies involved in making government information available to citizens. The theoretical framework will be used to analyze the case and evaluate possible information strategies.

\subsection{General strategy}

Recent developments in politics and society lead to a change in the strategy of RWS. Instead of primarily working alone in performing its task, RWS now presents itself as a director in a network of involved organizations, not only in regard to the traffic circulation but also in regard to organizations active on the market. RWS realizes that in carrying out its tasks an intensive cooperation with other organizations involved in network management is needed, as well as a way of thinking, acting and communicating that can transcend borders between organizations. So on behalf of the citizen, RWS is developing itself to a more recognizable and service oriented organization. This general strategy sketches the context for RWS' information strategy. Three partly contradicting preferences form the basis for this strategy.

\subsection{Preferences}

RWS is searching for news ways to enhance its legitimacy. As an organization, RWS has a history of more then 200 years, starting in water management. The social importance of the core functions of 
RWS has been undisputed until recently. No matter how sound the reputation of RWS has been, the organization will not be judged on what it did in the past, but on what it does now and on its future actions. For this, it is relevant to notice that RWS is increasingly confronted with citizens that demand more freedom of choice, more independence and less intervention of government. At the same time these citizens want more value for the taxes they pay. This demands for RWS to actively think in a customer oriented and at the same time businesslike way with citizens in dealing with problems on the roads and on the water. Direct communication and better services to citizens are regarded as ways to enhance their legitimacy.

Effectiveness is also an issue in this case. A core task of RWS is to provide adequate traffic facilities. This task is proving to be extremely difficult in such a densely populated country as the Netherlands with the highest car density per square kilometer in the world. Building roads and implementing traffic information systems is important and, additionally, RWS is searching for ways to influence the behavior of drivers in a desired direction. This means that they should, individually, make choices to stay away from traffic jams. To be able to make these decisions, citizens need to have information on traffic.

Efficiency is an important issue for RWS since national budgets are tight. The demands on RWS to become more efficient are growing nowadays. Government in general and therefore also RWS needs to strive for a better performance on their core functions. This means that these functions should be carried out more efficiently and in a much more service oriented manner. There is also a need for less bureaucracy. The management thinks that RWS should be arranged in a much simpler and more uniform way. Furthermore, RWS should think more in terms of results and become more sensitive to costs of operations. Selling information to commercial parties would be a way to enhance profit and, concurrently, provide relevant information to citizens. In this sense, the contract with the VID and others can be regarded as efficient. The preferences indicate what RWS wants to achieve through its information strategy. The options for this strategy are influenced by the presence of other actors, intermediaries and competitors, in this policy field.

\subsection{Other actors}

Information intermediaries play a crucial role in this field. As described earlier, RWS stated in a policy document that the government should stimulate the development and exploitation of travel information services. However the development and exploitation itself should not be seen as a government task. Based on this policy RWS chooses to use intermediaries to release real-time traffic information to the public. RWS uses a few intermediaries for this. The relation between RWS and its intermediaries is shaped as part of formal and informal rules. For the judge this was an important consideration in the lawsuit. Besides intermediaries, RWS is also confronted with new competitors that can also generate real-time traffic information. These new competitors are private market organizations which make smart use of new options offered by modern information and communication technology. In doing so they are able to generate a much more accurate, faster and more detailed picture of the actual travel times than current solutions with total investments which are a fraction of the current, road side equipment based solutions. This can be seen as a direct threat for the position of RWS in this regard.

\subsection{Institutional context}

The three elements of the institutional context that are relevant to understanding this case are discussed here. 
- Legislation. There are no laws that prohibit RWS from publishing the traffic information and making it available to the public. Nevertheless, the ministry adopted a policy rule in 1998 which stated explicitly that it will not develop its own travel information services. RWS cannot decide to make this information available to the public without changing this policy rule.

- Political context. The political climate broadly favors for government organizations to make information available to the public. Politicians emphasize that making information available fits a modern society and therefore new initiatives are being developed to enhance public access to government information.

- Informal rules. The informal rules are in line with the policy rules. Other actors expect that they can buy the information from RWS and make it available to the public through their websites. This practice has developed over time.

In the institutional context, there is a tension between the legal and informal rules that stipulate that RWS should make the information available to the general public through intermediaries and the political context which highlights the importance of making information available to citizens. Legal and informal rules are in line with the preferences concerning efficiency; the political context puts the emphasis on legitimacy.

\subsection{Strategic options}

Given RWS' overall strategy, preferences, other actors and the institutional context, RWS has several main options for creating an information arrangement.

- No information made available. Not offering the information to the general public is not a serious option in this case. Not offering the information would seriously affect RWS' legitimacy and effectiveness, at the same time decrease its efficiency since no extra funds would be generated. Advantages of this option are that it is equitable (since nobody has access) and manageable (since RWS does not have to manage external access to its databases).

- Offering the information directly to citizens. RWS has thought about offering the information to the general public through its own website. Offering the information is equitable and a way to enhance its legitimacy. Citizens will appreciate the availability of the information. Offering the information for free would decrease its efficiency since the additional resources from the contract with the VID will be lost. It will also confront RWS with the problems of managing external access to a database. Doing this would require a change in its policy rules and also in the informal rules that guide their contact with other actors.

- Selling the information to intermediaries. The current practice is that RWS sells the information to intermediaries such as the VID. This method ensures that the information is being made available in a professional manner and end-users can find their way to these websites. Selling the information has a positive impact on RWS' efficiency and manageability. A disadvantage is that RWS itself is not visible in this strategy and therefore the information does not help to improve RWS's legitimacy. Another disadvantage is that end-users probably will have to pay for the information which affects the equity of the arrangement negatively. This fact could limit the effectiveness since fewer citizens will use the information when they have to pay for it.

- Giving the information to intermediaries. RWS could decide to make the information available for free to intermediaries. The disadvantage is that RWS will not make any money through this strategy. On the other hand, it will also not face the cost and worries of having to make the information available through an RWS website. Since commercial parties will want to make a profit, access could be limited to paying users and this equity and effectiveness of the arrangement could decrease. 
Table 1

Consequences of information strategies in terms of preferences

\begin{tabular}{|c|c|c|c|c|c|}
\hline Information strategy & Legitimacy & Effectiveness & Equity & Cost-effectiveness & Manageability \\
\hline 1. No information made available & Very low & Low & High & Low & High \\
\hline $\begin{array}{l}\text { 2. Offering the information directly to } \\
\text { citizens }\end{array}$ & Very high & High & High & Very low & Low \\
\hline $\begin{array}{l}\text { 3. Selling the information to } \\
\text { intermediaries }\end{array}$ & Low & Medium & Low & Very high & High \\
\hline $\begin{array}{l}\text { 4. Giving the information to } \\
\text { intermediaries }\end{array}$ & Low & Medium & Low & Low & High \\
\hline
\end{tabular}

These four options have different consequences for RWS legitimacy. The results are shown in Table 1.

\subsection{Choice}

The various strategies offer different advantages. 'No information made available' only offers advantages in terms of equity (but in a rather awkward way) and manageability. The other strategies offer advantages in terms of efficiency, effectiveness and legitimacy. A choice for these options can be made on the basis of an emphasis on the preferences. If legitimacy and effectiveness are the key preferences, RWS could choose to offer the information directly to citizens. It will need to change the institutional context and accept the costs of making the information available. The present strategy, selling the information to intermediaries, is very cost-effective in the sense that it offers an opportunity to earn back some of the costs involved in gathering the information. However it offers no gains in terms of legitimacy and its level of effectiveness can be considered as medium (in general only citizens are reached who are willing to pay to the intermediaries). The option 'Giving the information to intermediaries' is comparable with option 3 as far as it concerns legitimacy.

The considerations could change if another argument is added to the matrix: the idea that RWS could condition the way in which commercial parties make the information available to the public. One of the conditions under which government hands over the data to intermediaries could be that this data must be disclosed to citizens for free. Under this condition, the effectiveness and equity of these options would also be 'high' since all users could access the information for free. Conditionalities are the key in considering creating access to the traffic information through intermediaries.

\section{Reflections}

In 2003 RWS chose to offer information directly to citizens (option 2) since the general strategy emphasized the need to focus on end-users and making information available. RWS decided to create a website with traffic information. This strategy crossed the formal and informal practices that had grown over the years: RWS made information available through intermediaries (option 3). This option had become less attractive since RWS wanted to increase its visibility in an effort to enhance its legitimacy and improve effectiveness. Offering the information directly to citizens, however, was not allowed for by the judge. RWS can either accept this ruling and fall back on option 3 or change its policy rules and prepare for option 2.

The case analysis shows that RWS has, so far, not changed its policy rules to prepare for option 2 . They seem to have changed their thoughts on option 3. Option 3 is increasingly seen as an option that fits the new strategy of being the director of a policy network that consists of various public and private organizations. RWS has acknowledged that it needs other organizations to perform its core tasks 
now and in the future. The network approach also applies to releasing traffic information. RWS has a history of operating in the background. Road users usually do not think of RWS when traffic information is concerned. In the Netherlands, for years now this kind of information is brought to road users by commercial organizations. Therefore, in comparison to RWS the present intermediaries have proven to provide for successful channels of communication with end users of the traffic information whereas RWS is not known for delivering information. This is not lamentable but a rational choice made by RWS itself. By using the strengths of each organization, RWS could be more successful in performing its key tasks. RWS is good at gathering information; intermediaries are good at making this information available to end-users. Cooperation could create a win-win situation and enhance the manageability of the arrangement.

Although RWS does seem to regard option 3 as a viable option, it has clear limitations. It has no effects on RWS legitimacy since RWS remains invisible. To increase the legitimacy RWS could think about handing over the information to intermediaries but only under certain conditions. We already mentioned granting free access as an important condition. Free access, however, is beneficial to citizens but does not show them that RWS has gathered this information for them. An additional condition could be that the intermediaries are required to state clearly that they have obtained the information from RWS. This could then be seen as a type of 'Intel inside' strategy. Every time citizens use the traffic information from an intermediary, they are always pointed to the fact that this information was originally provided by RWS. This latter can then serve as a kind of quality label. The 'RWS inside' strategy offers benefits to both RWS and intermediaries. RWS increases its visibility and commercial parties will still be able to make a profit through this information. Adding this kind of conditions is possible for option 3 as well as option 4 . Although, in the case of option 4 government is probably more in a position to formulate conditions. Effectiveness could be increased if intermediaries were to offer the information for free. Within option 4 this could also be one of the conditions under which the government gives the information to intermediaries. Formulating such a condition is much harder in option 3 because the intermediaries should have a chance to earn back their investments with regard to the information. However, it is not unthinkable to make such a deal within option 3. Instead of charging citizens a fee for using the information, they could make a profit through commercial advertisements.

One of the elements of the framework presented in this paper is the institutional context. In the case the importance of this context for information arrangements was stressed by the fact that some developments in the institutional context of RWS are expected to have serious implications for current and possible future information arrangements. Think for example of the cooperation between Vodafone and TomTom. Attention for these new developments as part of the institutional context makes clear that current arrangements should be adjusted over time or even can become obsolete. With regard to traffic information new developments could lead to totally new arrangements in which RWS becomes a consumer of actual real-time traffic information instead of a producer. This can turn out to be more efficient. As a result, RWS should not only evaluate its current information arrangement with regard to the release of traffic information, but should also explore new arrangements regarding the obtaining of this kind of information.

\section{Conclusions}

Our conclusion is that the framework we developed on the basis of the literature [10-12,14-16,18,19] helped to analyze the strategic options for information management and is suited to explain the variety of choices in a real setting. It turned out that the framework can be used in three different ways. 
In the first and most important way the framework can be used is to identify and name elements that are important in choosing and understanding a certain information arrangement of a government organization. By focussing on these elements it can be made clear that there is a distinction between policy and politics. Politics is about deciding what the weight of the different preferences should be, policy is about choosing the best alternative in view of the chosen weight factors (see also [13]). We highlighted the importance of 'conditionality' as a key factor in designing adequate policies.

Secondly, with regard to the information policy (the information arrangement), the case shows that RWS has options to influence the outcomes of some preferences. For example, by formulating conditions under which intermediaries can make use of the traffic information, the legitimacy of RWS could be increased from 'low' to 'high'. Following the same line of reasoning, the effectiveness of the strategic choice to provide the information through intermediaries could be raised. However insight in the consequences of information strategies in terms of preferences and options to change these consequences does not automatically imply a choice between the options. Valuing the preferences is a matter of politics. The framework can help to make the consequences of information strategies more clear and thus support decision-making on these strategies. It can however, not replace the political decision making process. For example, the cost-effectiveness is very low if the agency itself offers the information to citizens. But the score on legitimacy and effectiveness is 'very high' and 'high'. If in the political decision making process it is decided that the preferences legitimacy and effectiveness have more value than the preference of cost-effectiveness, choosing to offer the information directly to citizens may very well be one of the desired options and the policy rules could be changed to prepare for this option.

Finally, the case shows that the framework is also suitable for reconstructing the considerations that played a role in certain choices made by government organizations. Based on this reconstruction it is possible to consider possible explanations for choices regarding certain information arrangement made by a government organization. The case also shows that the choice by RWS for a certain information arrangement (and the attempt to change this arrangement) was mainly determined by considerations that have to do with legitimacy and efficiency (cost-effectiveness). By zooming in on this and by looking at the interaction between the institutional context and the rational choices it becomes clear which considerations come into play for government organizations in determining their information arrangements. The framework provides an option to systematically examine the meaning of new developments for current information arrangements.

\section{References}

[1] D.M. West, Digital Government. Technology and Public Sector Performance, Princeton University Press, 2005.

[2] I.Th.M Snellen and W.B.H.J. Van de Donk, eds, Public Administration in an Information Age, A Handbook, IOS Press, 1998.

[3] J.E. Fountain, Building the Virtual State. Information Technology and Institutional Change, The Brookings Institute, 2001.

[4] S. Borins, K. Kernaghan, D. Brown, N. Bontis, Perri 6 and F. Thompson, Digital State at the Leading Edge, University of Toronto Press, 2007.

[5] R. Heeks, Implementing and Managing eGovernment. An International Text, Sage Publications, 2006.

[6] S. Zuboff, In the Age of the Smart Machine. The Future of Work and Power, Basic Books, 1989.

[7] A.M. Kjaer, Governance, Polity Press, 2004.

[8] W. Eggers, Government 2.0. Using Technology to Improve Education, Cut Red Tape, Reduce Gridlock, And Enhance Democracy, Rowman \& Littlefield Publishers, 2005.

[9] S. Goldsmith and W. Eggers, Governing By Network. The New Shape of the Public Sector, Brookings Institution Press, 2004.

[10] H.A. Simon, Administrative Behavior: A Study of Decision-making Processes in. Administrative Organization, The Free Press, 1947. 
[11] M. Suchman, Managing Legitimacy: Strategic and Institutional Approaches, Academy of Management Review 3 (1995), 571-610.

[12] P. John, Analysing Public Policym, Continuüm, 1998

[13] Perri 6, E-Governance. Styles of Political Judgment in The Information Age Polity, Palgrave, 2006.

[14] L.M. Salamon,, The Tools of Government. A Guide to the New Governance, Oxford University Press, 2002.

[15] D. Curtin and A.J. Meijer, Does transparency strengthen legitimacy? Information Polity 2 (2006), 109-122.

[16] A.J. Meijer, Publishing public performance results on the Internet. Do stakeholders use the Internet to hold Dutch public service organizations to account? Government Information Quarterly 1 (2007), 165-185.

[17] A. Edwards, De gefaciliteerde democratie: internet, de burger en zijn intermediairen, Lemma, 2003.

[18] J.G. March and J.P. Olsen, Rediscovering Institutions: The Organizational Basis of Politics, The Free Press, 1989.

[19] P.A. Hall and R.C.R. Taylor, Political Science and the Three New Institutionalisms, Political Studies 5 (1996), 936-957.

[20] A. Giddens, The constitution of society: outline of the theory of structure, University of California Press, 1984.

[21] W.J. Orlikowski, The Duality of Technology: Rethinking the Concept of Technology in Organizations, Organization Science 3 (1992), 398-427.

[22] TomTom, TomTom and Vodafone Netherlands to develop the world's most advanced travel time information system for the Connected Car. DOI= http://www.mobility.tomtom.com/news/index.php?NID=1\&Year=2006\&Languag e=1, 2006.

[23] Directorate-General for Public Works and Water Management, Een nieuw perspectief voor Rijkswaterstaat. Doorpakken, wel degelijk, Den Haag, 2004.

[24] Directorate-General for Public Works and Water Management, Beter geïnformeerd de weg op door nauwkeuriger verkeersinformatie. DOI= http://www.verkeerenwaterstaat.nl/actueel/nieuws/betergenformeerddewegopdoornauwkeuri gerverkeersinformatie.aspx, 2007.

[25] NRC Handelsblad, Het Rijk bepaalt straks waar je rijdt. Met nieuwe databank vol gegevens wil overheid automobilist meer sturen en files bekorten, p. 23, 8 December 2007.

[26] Financieele Dagblad, Verkeersdienst van TomTom moet het fileleed verzachten, p. 19, 13 November 2007.

[27] Nederlands Dagblad, TomTom ziet file via gegevens bellers, p. 9, 13 November 2007.

[28] Verdict on the 4th of August 2003, nr. KG 03/625, Court The Hague, Sector Civil Law. 